\title{
幼苗期淹水胁迫及喷施烯效唑对小豆生理和产量的影响
}

\author{
项洪涛 $^{1}$ 李 琬 ${ }^{1}$ 郑殿峰 ${ }^{2,3,{ }^{*}}$ 王诗雅 $^{3}$ 何 宁 $^{1}$ 王曼力 $^{1}$ 杨纯杰 $^{1}$ \\ 1 黑龙江省农业科学院耕作栽培研究所, 黑龙江哈尔滨 $150086 ;^{2}$ 广东海洋大学滨海农业学院, 广东湛江 $524088 ;^{3}{ }^{\text {黑龙江八一农晆 }}$ \\ 大学农学院, 黑龙江大庆 163319
}

摘 要: 为探究幼苗期淹水胁迫及喷施烯效唑(S3307)对小豆(Vigna angularis)生理代谢和产量的影响, 本研究于 2018一-2019 年以龙小豆 4 号和天津红为试验材料, 盆栽条件下, 苗期进行预喷施 S3307, 同时连续淹水处理 $5 \mathrm{~d}$ 并每 天取样, 测定分析相关生理指标。结果表明, 幼苗期淹水胁迫引起小豆叶片 $\mathrm{H}_{2} \mathrm{O}_{2}$ 和 MDA 含量、脯氨酸和可溶性蛋 白含量显著提高, ABA、IAA 和 SA 含量显著提高, SOD、POD 和 CAT 活性显著提高, 淹水处理 $5 \mathrm{~d}$ 导致龙小亘 4 号 单盆产量显著下降 $8.40 \% \sim 12.61 \%$, 天津红显著下降 9.91\% 10.01\%。S3307 具有抵御淹水胁迫的作用, 能有效增加小 豆叶片脯氨酸和可溶性蛋白含量, 显著降低 $\mathrm{H}_{2} \mathrm{O}_{2}$ 和 MDA 含量, 能够显著提高 SOD 和 POD 活性以及 SOD/POD、 $\mathrm{SOD} / \mathrm{CAT}$, 显著增加 ABA 和 SA 含量, 并显著抑制 IAA 含量的上升。喷施 S3307 使淹水 $4 \mathrm{~d}$ 的龙小亚 4 号产量显著 提高 2.85\% 6.18\%, 使天津红淹水 $4 \mathrm{~d}$ 的产量显著提高 $2.85 \% \sim 3.95 \%$ 。综上, 淹水胁迫下, 不同品种小豆在活性氧物 质积累、膜质过氧化、抗氧化酶活性以及激素水平等方面的生理应激存在显著差异; 喷施 S3307 能够有效缓解淹水 胁迫对小豆生理和产量的影响。本研究结果为进一步研究小豆苗期抵御淹水胁迫的生理机制及提高淹水胁迫下小豆 的产量提供理论依据。

关键词: S3307; 小豆; 淹水胁迫; 叶片生理; 产量

\section{Effects of uniconazole and waterlogging stress in seedling stage on the physio logy and yield in adzuki bean}

\author{
XIANG Hong-Tao ${ }^{1}$, LI Wan ${ }^{1}$, ZHENG Dian-Feng ${ }^{2,3, *}$, WANG Shi-Ya ${ }^{3}$, HE Ning ${ }^{1}$, WANG Man-Li ${ }^{1}$, and \\ YANG Chun-Jie ${ }^{1}$

\footnotetext{
${ }^{1}$ Institute of Crop Cultivation and Tillage, Heilongiiang Academy of Agricultural Sciences, Harbin 150086, Heilongjiang, China; ${ }^{2}$ College of Coastal Agriculture Sciences, Guangdong Ocean University, Zhanjiang 524088, Guangdong, China; ${ }^{3}$ College of Agriculture, Heilongjiang Bayi Agriculture University, Daqing 163319, Heilongjiang, China
}

\begin{abstract}
In order to explore the difference on the resistance physiology and yield and the mitigation effect of uniconazole (S3307) pretreatment under waterlogging stress, the pot experiment was conducted using Longxiaodou 4 (LXD 4) and Tianjinhong (TJH). The anti-stress physiological indexes and yield were measured on 5th day after waterlogging stress and foliar spraying S3307 at seedling stage, and samples were taken every day. The results showed that leaf physiological indexes in waterlogging stress were changed during seedling stage, the content of $\mathrm{H}_{2} \mathrm{O}_{2}, \mathrm{MDA}$, proline and soluble protein were significantly increased, as the same as the content of ABA, IAA, and SA, and the activities of SOD, POD, and CAT. Waterlogging treatment for five days resulted in a significant decrease in the output of LXD 4 in a single pot by $8.40 \%$ to $12.61 \%$, and that of TJH decreased by $9.91 \%$ to $10.01 \%$. S3307 had the effect of resisting waterlogging stress, and could effectively increase the content of proline and soluble protein in the leaf of adzuki bean, significantly reduced the content of $\mathrm{H}_{2} \mathrm{O}_{2}$ and MDA, significantly increased the activity of SOD and POD, the value of SOD/POD and SOD/CAT, significantly increased the ABA and SA content, and significantly inhibited the increase in IAA content. Foliar spraying S3307 significantly increased the output of LXD 4 by $2.85 \%$ to $6.18 \%$ under waterlog-
\end{abstract}

本研究由国家自然科学基金项目(31871576)和国家现代农业产业技术体系建设专项(CARS-08-04B)资助。

This study was supported by the National Natural Science Foundation of China (31871576) and the China Agriculture Research System (CARS-08-04B).

*通信作者(Corresponding author): 郑殿峰, E-mail: zdffnj@263.net

第一作者联系方式: E-mail: xianght@163.com

Received (收稿日期): 2020-03-17; Accepted (接受日期): 2020-10-14; Published online (网络出版日期): 2020-11-06.

URL: https://kns.cnki.net/kcms/detail/11.1809.S.20201105.1127.006.html 
ging treatment for four days, and significantly increased the yield of TJH by $2.85 \%$ to $3.95 \%$, respectively. This study concluded that there were significant differences under physiological stress in reactive oxygen species accumulation, membrane lipid peroxidation, antioxidant enzyme activities and hormone levels among different varieties of adzuki bean under waterlogging stress. Spraying S3307 could effectively alleviate the effects of waterlogging stress on the physiology and yield in adzuki bean. The results provide a theoretical basis for further studying the physiological mechanism of adzuki bean resistance to waterlogging at the seedling stage and improving the yield of adzuki bean under waterlogging stress.

Keywords: uniconazole (S3307); adzuki bean; waterlogging stress; leaf physiology; yield

近年来全球气候变暖, 极端天气及洪涝灾害频 发, 淹水胁迫已经成为农业生产中最常见的非生物 逆境胁迫之一 ${ }^{[1]}$ 。据统计, 在全球范围内 $10 \%$ 的灌溉 土地受到洪涝灾害的影响，这可能会降低 $20 \%$ 农作 物产量 ${ }^{[2]}$ 。涝害是我国第二大自然灾害，我国农业水 灾受灾面积占总受灾面积的 $19 \%$ 左右 ${ }^{[3]}$ 。小五是我 国重要的食用豆类作物之一, 是重要的种植结构调 整作物, 有利于我国农业可持续发展。小亚具有适 应性强和播种范围广等特点, 其耐痊薄、耐盐碱, 但 对淹水胁迫敏感，我国春播地区的春涝、夏播地区 的多雨都会对小豆苗期生育造成水分胁迫, 极易形 成淹水危害。

淹水胁迫抑制植株幼苗生长, 造成植株个体生 理差异, 最终降低作物产量, 影响农业生产 ${ }^{[4]}$ 。淹水 胁迫能诱导细胞产生自由基, 进而导致离子渗漏和 细胞死亡, 为抵御淹水胁迫下活性氧(reactive oxygen species, ROS)的毒害作用, 植物体内的抗氧化酶 类活性提高, 能够清除更多的自由基。研究表明, 高 水平的超氧化物歧化酶 (superoxide dismutase, SOD)、过氧化物酶(peroxidase, POD)和过氧化氢酶 (catalase, CAT)活性在长时间淹水条件下多种植物 的存活中发挥重要作用 ${ }^{[5]}$ 。淹水逆境下, 植物 ROS 代谢失衡, 导致过氧化氢 $\left(\mathrm{H}_{2} \mathrm{O}_{2}\right)$ 、超氧根阴离子 $\left(\mathrm{O}_{2}{ }^{-}\right)$ 等过度积累, 过多的 ROS 会引起膜系统损伤和细胞 氧化 ${ }^{[6]}$, 生成过氧化脂质并随后逐渐分解成一系列 复杂的化合物, 其中包括丙二醛 (malondialdehyde, MDA), MDA 能与酶蛋白发生链式反应聚合, 引起 膜系统变性影响正常生理代谢, 最终导致产量下 降。研究表明, 玉米苗期淹水胁迫 3 7 d 后产量下降 $58.80 \% \sim 69.80 \%{ }^{[7]}$, 绿豆始粒期淹水胁迫可减产 $18.07 \% \sim 28.87 \%{ }^{[8]}$ ，大豆 V3 期淹水导致单株产量下 降 $11.11 \%$ [9]。近年来, 通过化控技术调控作物生理 代谢、增强抗逆性以缓解胁迫以及提高作物产量已 被广泛认可。烯效唑(uniconazole), 简称 S3307, 是 一种具有广谱、高效、低毒低残留特点的植物生长 延缓剂, S3307 有提高作物产量的作用, 常被用在调 控作物生长发育、增强抗逆性等方面 ${ }^{[10]}$ 。始花期喷
施 S3307 能降低淹水胁迫条件下大豆 MDA 含量并 提高 SOD 和 POD 活性, 提高脯氨酸和可溶性糖等 物质的含量 ${ }^{[11]}$ 。始花期喷施 S3307 能提高胁迫条件 下小五 SOD、POD 和 CAT 活性, 并显著提高产量 $23.06 \%$ 43.88\% ${ }^{[10]}$ 。于奇等 ${ }^{[8]}$ 也指出, 喷施 $\mathrm{S} 3307$ 可有效提高淹水胁迫下绿豆叶片的生理功能进而降 低减产幅度。赵宏伟等 ${ }^{[12]}$ 、梁晓艳等 ${ }^{[13]}$ 、刘洋等 ${ }^{[14]}$ 研究表明, 在水稻、大豆、绿豆等作物上应用 S3307 具有显著抗逆和增产效应。关于淹水胁迫对作物影 响的研究多集中在大豆、玉米、水稻、西甜瓜、白 菜等作物上, 较少涉及小豆, 且关于 S3307 缓解小 豆苗期淹水胁迫的研究尚末见报道。

当小互受到淹水胁迫时, 叶片生理代谢受阻并 影响幼苗建植, 最终导致产量下降。因此本试验于 幼苗期对小五进行淹水处理, 开展淹水胁迫及预喷 施 S3307 对小五叶片抗逆生理及产量的影响研究, 旨在分析 S3307 抵御小豆苗期淹水的作用, 以期为 小互抗涝栽培提供理论支持。

\section{1 材料与方法}

\section{1 试验材料}

供试小豆(Vigna angularis)品种为 ‘龙小亘4号”和 ‘天津红', 由国家食用豆产业技术体系芸五育种岗位 专家魏淑红研究员馈赠。供试植物生长调节剂为 S3307, 由黑龙江八一农良大学化控研究中心提供。

\section{2 试验设计}

试验于 2018-2019 年在黑龙江省农业科学院 耕作栽培研究所盆栽场及人工气候室内进行。试验 采用盆栽方式, 盆高 $23 \mathrm{~cm}$ 、直径 $25 \mathrm{~cm}$, 每盆装自 然风干壤土 $5.5 \mathrm{~kg}$, 播种后覆土 $200 \mathrm{~g}$, 每盆保苗 15 株(5 穴 $\times 3$ 株)。试验用土取自哈尔滨市道外区民主 乡, 土壤类型为草甸黑土。供试土壤的理化性质: 土 壤容重约为 $1.72 \mathrm{~g} \mathrm{~cm}^{-3}$, 最大田间持水量约为 $25.65 \%$, 含有机质含量 $2.63 \%$ 、全氮 $1.46 \mathrm{mg} \mathrm{g}^{-1}$ 、 全磷 $0.66 \mathrm{mg} \mathrm{g}^{-1}$ 、缓效钾 $325.70 \mathrm{mg} \mathrm{kg}^{-1}$ 、碱解氮 $165.00 \mathrm{mg} \mathrm{kg}^{-1}$ 、速效磷 $41.25 \mathrm{mg} \mathrm{kg}^{-1}$ 、速效钾 156.7 $\mathrm{mg} \mathrm{kg}^{-1}$, 土壤 $\mathrm{pH}$ 6.69。4 月 18 日播种(阳光型人工 
气候室内播种，哈尔滨地区 4 月中旬室外温度相对 偏低, 不利出苗), 每品种分别播种 100 桶, 选取长 势均匀的 90 盆材料进行试验, 其中每处理使用 30 盆, 指定 15 盆用来生理取样, 剩余 15 盆用来测产。 试验共设 6 个处理, 每个处理设 3 次重复, 具体设计 见表 1。待植株生长至幼苗期(此时真叶完全展开, 第一片复叶露头)进行处理。处理当天上午 9:00, 采 取叶面喷施方式施用 S3307, 施用浓度为 $20 \mathrm{mg} \mathrm{L}^{-1}$ (该浓度系本课题组前期浓度比较试验篮选所得), 折合用液量为 $22.5 \mathrm{~mL} \mathrm{~m}^{-2}$ 。喷施 $24 \mathrm{~h}$ 后, 于翌日上
午 9:00 进行淹水处理, 淹水处理采取套盆方式, 淹 水程度以水面高于土壤表面 $1.5 \sim 2.0 \mathrm{~cm}$ 为准, 以适 宜土壤含水量为对照(相对含水量为 $70 \% \sim 80 \%$ )。淹 水 $24 \mathrm{~h}$ 后, 进行第一次取样, 之后每天上午 9:00 顺 延进行下一次取样, 本试验共取样 $5 \mathrm{~d}$, 记为取样 $1 \sim 5 \mathrm{~d}$ 。同时各处理在取样期间每天去除套盆、解除 淹水胁迫 3 盆, 逐步恢复正常土壤含水量, 供后期 产量测定使用。对解除胁迫的盆栽，每日观察并陆 续进行间苗、拔草等, 最终每盆保苗 5 株(5 穴 $\times 1$ 株), 根据实际气温和降雨情况, 适时浇水直至成熟。

表 1 试验设计方案

Table 1 Experiment design

\begin{tabular}{lccl}
\hline \multicolumn{1}{c}{$\begin{array}{c}\text { 品种 } \\
\text { Variety }\end{array}$} & $\begin{array}{c}\text { 处理编号 } \\
\text { Treatment code }\end{array}$ & $\begin{array}{c}\text { 药剂处理 } \\
\text { Pesticide treatment }\end{array}$ & $\begin{array}{c}\text { 水分处理 } \\
\text { Water treatment }\end{array}$ \\
\hline 龙小豆 4 号 & $\mathrm{T} 1$ & 蒸馏水喷施 Spray water & 正常土壤水分 Suitable soil moisture \\
Longxiaodou 4 & $\mathrm{~T} 2$ & 蒸馏水喷施 Spray water & 淹水胁迫 Waterlogging stress \\
& $\mathrm{T} 3$ & $\mathrm{~S} 3307$ 喷施 Spray S3307 & 淹水胁迫 Waterlogging stress \\
天津红 & $\mathrm{T} 4$ & 蒸馏水喷施 Spray water & 正常土壤水分 Suitable soil moisture \\
Tianjinhong & $\mathrm{T} 5$ & 蒸馏水喷施 Spray water & 淹水胁迫 Waterlogging stress \\
& $\mathrm{T} 6$ & $\mathrm{~S} 3307$ 喷施 Spray S3307 & 淹水胁迫 Waterlogging stress \\
\hline
\end{tabular}

\section{3 测定指标与方法}

1.3.1 取样方法各处理分别进行取样, 将小亘 植株叶片迅速剪下装入事先标记好的自封袋内，并 立即放入液氮中, 充分冷冻后置于 $-80^{\circ} \mathrm{C}$ 冰箱中保 存，供测定生理指标使用。

1.3.2 测定方法使用试剂盒测定过氧化氢 $\left(\mathrm{H}_{2} \mathrm{O}_{2}\right)$ 含量。采用氮蓝四唑 $(\mathrm{NBT})$ 法测定超氧化物歧 化酶(SOD)活性, 采用愈创木酚法测定过氧化物酶 (POD)活性, 采用分解过氧化氢含量速率法测定过 氧化氢酶(CAT)活性，采用硫代巴比妥酸(TBA)法测 定丙二醛(MDA)含量, 采用考马斯亮蓝 G-250 染色 法测定可溶性蛋白含量, 具体操作规程按照李合生 等 ${ }^{[15]}$ 的方法。采用硫酸蒽酮比色法测定可溶性糖含 量, 采用狮三酮比色法测定脯氨酸含量, 具体操作 规程按照张宪政等 ${ }^{[16]}$ 的方法。

采用高效液相色谱质谱联用法测定激素水平。 (1)提取: 取 $0.2 \mathrm{~g}$ 植株组织样品, 加入 $10 \mathrm{~mL}$ 甲醇水-甲酸溶液充分研磨离心 $(3000 \times g 、 5 \mathrm{~min})$, 上清液 $+\mathrm{Vc}$-乙醇溶液浓缩至水相, (2)净化: 过 Oasis HLB 固相萃取柱，用 $1 \mathrm{~mL} 20 \%$ 甲醇 $+1 \mathrm{~mL} 80 \%$ 甲醇溶 液先后清洗萃取柱, 样液过 $0.22 \mu \mathrm{m}$ 有机滤膜, 供 HPLC-MS/MS 分析。液相色谱和质谱条件参照范建 新等 ${ }^{[17]}$ 的方法: Poroshell 120 SB-C18 反相色谱柱
$(2.1 \times 150,2.7 \mu \mathrm{m})$; 线性洗脱梯度: 0 2 $\mathrm{min}, \mathrm{A}=$ 20\%; 2 4 min, A 递增至 50\%; 4 10 min, A 递增至 $80 \%$; 10 11 min, A80\%；11.1 min, A 递减至 20\%; $11.1 \sim 15.0 \mathrm{~min}, \mathrm{~A} 20 \%$ 流速为 $0.6 \mathrm{~mL} \mathrm{~min}$, 柱温 $30^{\circ} \mathrm{C}$, 样品盘温度 $4^{\circ} \mathrm{C}$, 进样量 $2 \mu \mathrm{L}$, 分析时间 $15 \mathrm{~min}$ 。

\section{4 数据处理}

利用 Microsoft Excel 2010 处理试验数据并作 图, 使用 DPS 软件选择新复极差法进行显著性差 异检验。

\section{2 结果与分析}

2.1 淹水胁迫及喷施 S3307 对小豆幼苗叶片膜损 伤的影响

2.1.1 对叶片 $\mathrm{H}_{2} \mathrm{O}_{2}$ 含量的影响 由图 1 可知, 幼 苗期淹水胁迫后，小豆叶片 $\mathrm{H}_{2} \mathrm{O}_{2}$ 含量呈快速升高趋 势。与 $\mathrm{CK}$ ( $\mathrm{T} 1$ 或 $\mathrm{T} 4$ )相比, 龙小豆 4 号和天津红均 表现为淹水胁迫 (T2 和 T5) 显著高于 $\mathrm{CK}_{0}$ 。喷施 S3307 后，有效降低了淹水胁迫下的小豆叶片 $\mathrm{H}_{2} \mathrm{O}_{2}$ 含量。 龙小亘 4 号处理 3 5 d 时, $\mathrm{T} 3$ 较 $\mathrm{T} 2$ 分别显著下降 $7.42 \% 、 11.88 \%$ 和 $21.06 \%$ 。天津红处理 1 5 d 时, T6 较 T5 分别显著下降 $10.03 \% 、 4.36 \% 、 11.18 \% 、 7.89 \%$ 和 $8.94 \%$ 。 


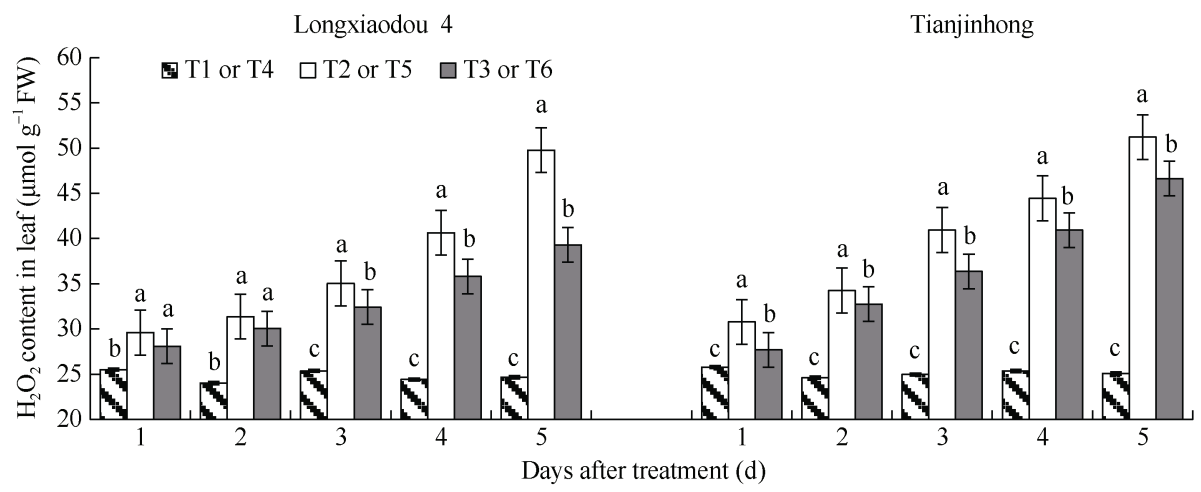

图 1 淹水胁迫及喷施 $\mathrm{S3307}$ 对小豆幼苗叶片 $\mathrm{H}_{2} \mathrm{O}_{2}$ 含量的影响

Fig. 1 Effects of waterlogging stress and spraying $\mathrm{S3307}$ on $\mathrm{H}_{2} \mathrm{O}_{2}$ content in leaf of seedlings of adzuki bean

T1 or T4: 幼苗期正常土壤水分, 喷施蒸馏水, 即对照; T2 or T5: 幼苗期土壤淹水胁迫, 喷施蒸馏水; T3 or T6: 幼苗期土壤淹水胁迫, 喷施 S3307。其中 $\mathrm{T} 1 \sim \mathrm{T} 3$ 对应龙小豆 4 号, T4 T6 对应天津红。同天内标以不同字母的值在 $P=0.05$ 水平上差异显著。

T1 or T4: normal soil moisture at seedling stage, and sprayed with distilled water, that is control; T2 or T5: exposed to waterlogging stress after spraying water at seedling stager; T3 or T6: exposed to waterlogging stress after spraying S3307 at seedling stage. Among them, T1-T3 corresponds to Longxiaodou 4, T4-T6 corresponds to Tianjinhong. Values of $\mathrm{H}_{2} \mathrm{O}_{2}$ content within the same day with different letters are significantly different at the 0.05 probability level.

\subsection{2 对叶片MDA含量的影响 由图2可知, 幼} 苗期淹水胁迫后, 小豆叶片MDA含量呈上升趋势。 龙小豆 4 号和天津红均表现为淹水胁迫 (T2 和 $\mathrm{T} 5$ ) 显 著高于CK (T1和T4)。喷施 $\mathrm{S} 3307$ 能明显缓解淹水胁 迫下MDA含量的提高。龙小豆 4 号处理 $2 \sim 5 \mathrm{~d}$ 时, T3 较 $\mathrm{T} 2$ 分别显著下降 $17.63 \% 、 15.11 \% 、 23.17 \%$ 和 $22.68 \%$ 。天津红处理 $3 \sim 5 \mathrm{~d}$ 时, T6较T5分别显著下降 $16.32 \% 、 23.73 \%$ 和 $20.01 \%$ 。

\section{2 淹水胁迫及喷施 $\mathrm{S3307}$ 对小豆幼苗叶片抗氧} 化酶系统的影响

\subsection{1 对叶片 SOD活性的影响 由图3可知, 小}

豆幼苗淹水及喷施S3307后, 叶片SOD活性整体呈 先升后降的变化趋势。龙小豆 4 号处理 $2 \mathrm{~d}$ 和 $3 \mathrm{~d}$ 时, $\mathrm{T} 2$ 较T1分别显著提高 $15.48 \%$ 和 $39.92 \%$ ，喷施S 3307 较
淹水胁迫相比提高了SOD活性, 但均未达到显著差 异水平。天津红处理 $2 \sim 4 \mathrm{~d}$ 时, T5较 $\mathrm{T} 4$ 分别显著提高 了 $25.49 \% 、 31.47 \%$ 和 $17.77 \%$, 淹水胁迫下喷施 $\mathrm{S} 3307$ 能有效提高天津红的SOD活性, 处理 $3 \sim 5 \mathrm{~d}$ 时, T6较 T5分别显著提高 $8.52 \% 、 11.52 \%$ 和 $9.33 \%$ 。

2.2.2 对叶片 POD活性的影响从图 4 可以看出, 幼苗期淹水处理后, 小豆叶片 POD 活性增强, 呈先 升高后降低的变化趋势。喷施 S3307 可进一步提高 $\mathrm{POD}$ 活性。龙小豆 4 号各时期均表现为 $\mathrm{T} 3>\mathrm{T} 2>\mathrm{T} 1$, 处理 1 4 d 时, $\mathrm{T} 2$ 较 $\mathrm{T} 1$ 分别显著提高了 $19.25 \%$ 、 $48.56 \% 、 73.40 \%$ 和 $62.38 \%$, 处理 $1 \sim 5 \mathrm{~d}$ 时, T3 较 T2 分别显著高出 $13.35 \% 、 12.96 \% 、 24.48 \% 、 41.39 \%$ 和 $32.94 \%$ 。天津红各时期均表现为 $\mathrm{T} 6>\mathrm{T} 5>\mathrm{T} 4$, 处理 $2 \sim 5 \mathrm{~d}$ 时, T5 较 T4 分别显著提高了 $54.14 \% 、 73.90 \%$ 、

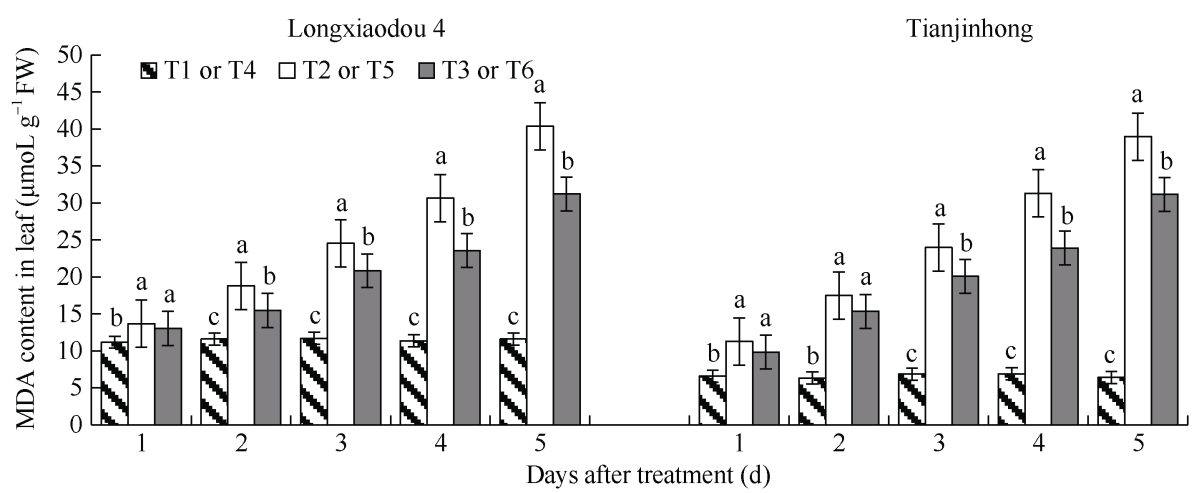

图 2 淹水胁迫及喷施 $\mathrm{S3307}$ 对小豆幼苗叶片 MDA 含量的影响

Fig. 2 Effects of waterlogging stress and spraying S3307 on MDA content in leaf of seedlings of adzuki bean 处理同图 1。同天内标以不同字母的值在 $P=0.05$ 水平上差异显著。

Treatments are the same as those given in Fig. 1. Values of MDA content within the same day with different letters are significantly different at the 0.05 probability level. 


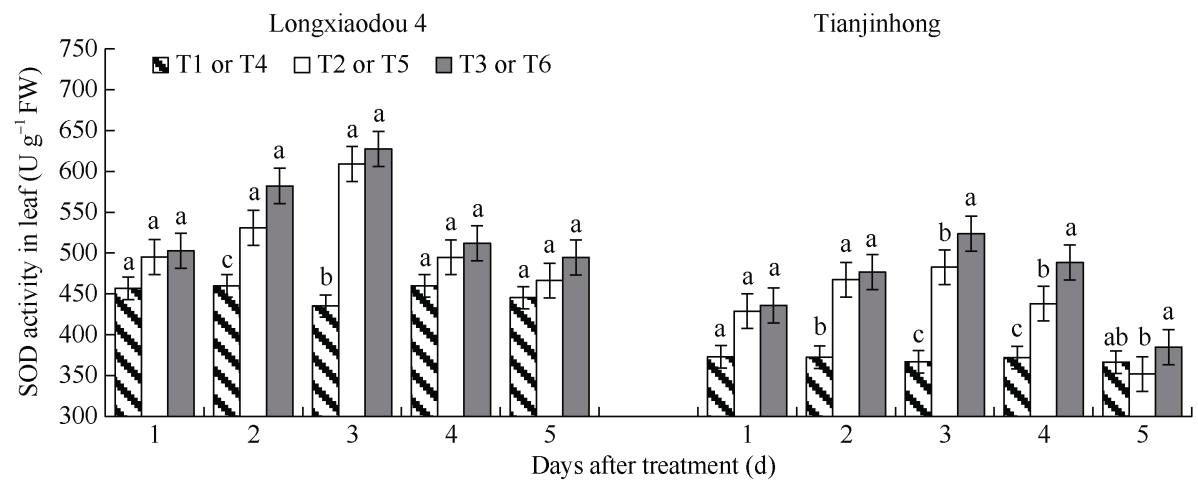

图 3 淹水胁迫及喷施 S3307 对小豆幼苗叶片 SOD 活性的影响

Fig. 3 Effects of waterlogging stress and spraying S3307 on SOD activity in leaf of seedlings of adzuki bean 处理同图 1。同天内标以不同字母的值在 $P=0.05$ 水平上差异显著。

Treatments are the same as those given in Fig. 1. Values of SOD activity within the same day with different letters are significantly different at the 0.05 probability level.

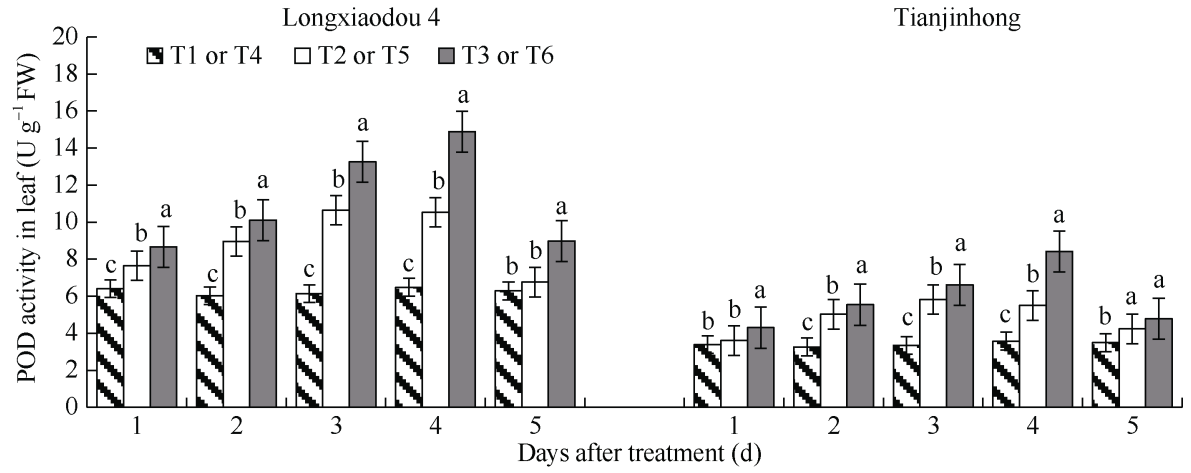

图 4 淹水胁迫及喷施 S3307 对小豆幼苗叶片 POD 活性的影响

Fig. 4 Effects of waterlogging stress and spraying S3307 on POD activity in leaf of seedlings of adzuki bean 处理同图 1。同天内标以不同字母的值在 $P=0.05$ 水平上差异显著。

Treatments are the same as those given in Fig. 1. Values of POD activity within the same day with different letters are significantly different at the 0.05 probability level.

$53.73 \%$ 和 $21.41 \%$, 处理 1 4 d 时, T6 较 T5 分别显著 高出 $19.44 \%$ 、10.36\%、13.63\%和 $53.16 \%$ 。

\subsection{3 对叶片 CAT 活性的影响 由图 5 可知, 幼} 苗期淹水及喷施 S3307 处理后，小豆叶片 CAT 活性 呈先升高后下降的变化趋势。龙小豆 4 号和天津红 的淹水处理均在第 3 天达到峰值, 在第 5 天时低于

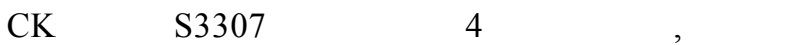
始下降。龙小亘 4 号处理第 3 天时 $\mathrm{T} 2$ 较 $\mathrm{T} 1$ 显著高 出 $40.96 \%$, 第 5 天时 $\mathrm{T} 2$ 较 $\mathrm{T} 1$ 显著降低 $24.61 \%$; 处 理 $2 \sim 5 \mathrm{~d}$ 时, $\mathrm{T} 3$ 较 $\mathrm{T} 2$ 分别显著提高了 $22.64 \%$ 、 $18.80 \%$ 、65.52\%和 $50.00 \%$ 。天津红处理 1 4 d 时, $\mathrm{T} 5$ 较 $\mathrm{T} 4$ 分别显著提高了 $19.25 \% 、 48.56 \% 、 73.40 \%$ 和 $62.38 \%$ ，第 5 天时, T5 较 T4 显著降低 $18.28 \%$; 处理 $1 \mathrm{~d}$ 和 $2 \mathrm{~d}$ 时, T6 较 T5 分别显著高出 $13.26 \%$ 和 $18.02 \%$, 处理 $4 \mathrm{~d}$ 和 $5 \mathrm{~d}$ 时, T6 较 T5 分别显著高出 $37.61 \%$ 和 $32.89 \%$ 。
2.2.4 对叶片 SOD/POD 的影响 由表 2 可知, 幼 苗期淹水及喷施 S3307 处理引起小豆叶片内 $\mathrm{SOD} / \mathrm{POD}$ 呈先下降后上升趋势。各处理均在第 4 天 达到谷值, 随后开始上升。龙小豆 4 号各时期均表 现为 $T 1>T 2>T 3$, 处理 $2 \sim 4 \mathrm{~d}$ 时, $\mathrm{T} 2$ 显著低于 $\mathrm{T} 1$, 喷 施 S3307 进一步降低了 SOD/POD, 处理 3 5 d 时, T3 较 T2 分别显著降低 $17.25 \% 、 26.71 \%$ 和 $20.68 \%$ 。天 津红各时期均表现为 $\mathrm{T} 4>\mathrm{T} 5>\mathrm{T} 6$, 处理 $2 \sim 5 \mathrm{~d}$ 时, T5 较 T4 分别显著降低了 $18.76 \% 、 24.89 \%$ 、23.36\%和 $20.86 \%$ ，处理 $4 \mathrm{~d}$ 时，T6 较 T5 显著降低 $27.49 \%$ ，其 他处理 $\mathrm{T} 6$ 和 $\mathrm{T} 5$ 之间差异不显著。

2.2.5 对叶片 SOD/CAT 的影响 由表 3 可知, 幼 苗期淹水对小互叶片 SOD/CAT 影响微弱, 龙小豆 4 号仅在处理 $5 \mathrm{~d}$ 时, T2 较 T1 显著高出 $26.56 \%$, 其他 时间淹水处理与对照之间没有显著差异, 天津红的 $\mathrm{T} 4$ 和 T5 之间在所有取样时期均无显著差异。喷施 


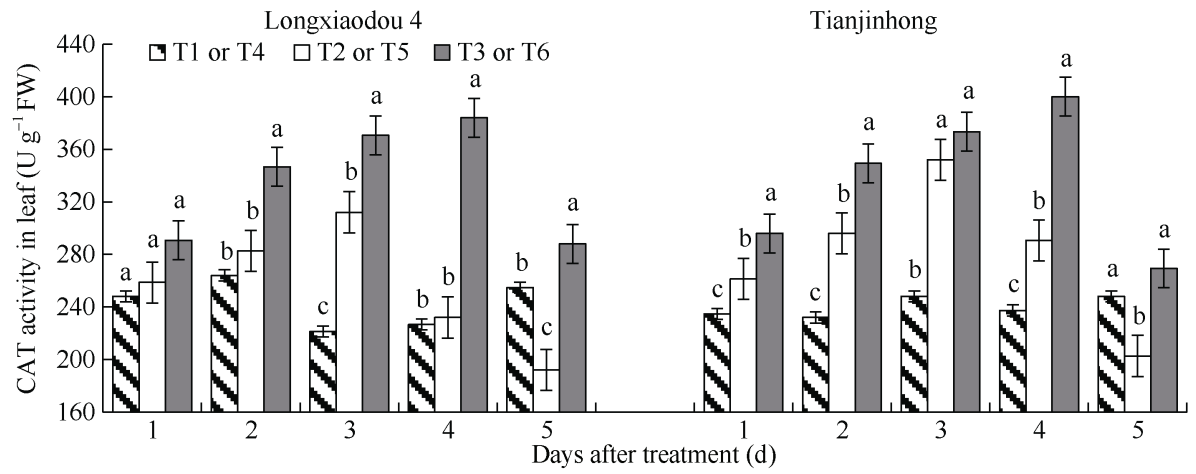

图 5 淹水胁迫及喷施 $\mathrm{S3307}$ 对小豆幼苗叶片 CAT 活性的影响

Fig. 5 Effects of waterlogging stress and spraying S3307 on CAT activity in leaf of seedlings of adzuki bean 处理同图 1。同天内标以不同字母的值在 $P=0.05$ 水平上差异显著。

Treatments are the same as those given in Fig. 1. Values of CAT activity within the same day with different letters are significantly different at the 0.05 probability level.

表 2 淹水胁迫及喷施 S3307 对小豆幼苗叶片 SOD/POD 的影响

Table 2 Effects of waterlogging stress and spraying S3307 on SOD/POD in leaf of seedlings of adzuki bean

\begin{tabular}{lccrcrc}
\hline \multirow{2}{*}{$\begin{array}{c}\text { 品种 } \\
\text { Variety }\end{array}$} & 处理 & \multicolumn{5}{c}{ 淹水天数 Waterlogging days } \\
\cline { 3 - 7 } & Treatment & $1 \mathrm{~d}$ & $2 \mathrm{~d}$ & $3 \mathrm{~d}$ & $4 \mathrm{~d}$ & $5 \mathrm{~d}$ \\
\hline 龙小豆 4 号 & $\mathrm{T} 1$ & $71.43 \pm 3.70 \mathrm{a}$ & $76.65 \pm 5.62 \mathrm{a}$ & $70.91 \pm 1.37 \mathrm{a}$ & $70.97 \pm 1.49 \mathrm{a}$ & $70.88 \pm 2.33 \mathrm{a}$ \\
Longxiaodou 4 & $\mathrm{~T} 2$ & $64.85 \pm 3.50 \mathrm{ab}$ & $59.38 \pm 1.44 \mathrm{~b}$ & $57.22 \pm 0.60 \mathrm{~b}$ & $46.99 \pm 1.72 \mathrm{~b}$ & $69.44 \pm 4.17 \mathrm{a}$ \\
& $\mathrm{T} 3$ & $58.03 \pm 0.97 \mathrm{~b}$ & $57.57 \pm 0.46 \mathrm{~b}$ & $47.35 \pm 0.06 \mathrm{c}$ & $34.44 \pm 2.03 \mathrm{c}$ & $55.08 \pm 1.84 \mathrm{~b}$ \\
天津红 & $\mathrm{T} 4$ & $110.40 \pm 0.69 \mathrm{a}$ & $114.73 \pm 5.30 \mathrm{a}$ & $110.45 \pm 7.66 \mathrm{a}$ & $104.55 \pm 6.06 \mathrm{a}$ & $105.39 \pm 3.77 \mathrm{a}$ \\
Tianjinhong & $\mathrm{T} 5$ & $119.88 \pm 7.58 \mathrm{a}$ & $93.21 \pm 2.98 \mathrm{~b}$ & $82.96 \pm 1.44 \mathrm{~b}$ & $80.13 \pm 5.13 \mathrm{~b}$ & $83.41 \pm 2.96 \mathrm{~b}$ \\
& $\mathrm{~T} 6$ & $101.79 \pm 5.16 \mathrm{a}$ & $86.03 \pm 2.10 \mathrm{~b}$ & $79.49 \pm 3.72 \mathrm{~b}$ & $58.10 \pm 1.13 \mathrm{c}$ & $80.90 \pm 3.51 \mathrm{~b}$ \\
\hline
\end{tabular}

处理同图 1。同天内标以不同字母的值在 $P=0.05$ 水平上差异显著。

Treatments are the same as those given in Fig. 1. Values of SOD/POD within the same day with different letters are significantly different at the 0.05 probability level.

\section{表 3 淹水胁迫及喷施 S3307 对小豆幼苗叶片 SOD/CAT 的影响}

Table 3 Effects of waterlogging stress and spraying S3307 on SOD/CAT in leaf of seedlings of adzuki bean

\begin{tabular}{lcccccc}
\hline \multirow{2}{*}{$\begin{array}{c}\text { 品种 } \\
\text { Variety }\end{array}$} & 处理 & \multicolumn{5}{c}{ 淹水天数 Waterlogging days } \\
\cline { 3 - 7 } & Treatment & $1 \mathrm{~d}$ & $2 \mathrm{~d}$ & $3 \mathrm{~d}$ & $4 \mathrm{~d}$ & $5 \mathrm{~d}$ \\
\hline 龙小豆 4 号 & $\mathrm{T} 1$ & $2.05 \pm 0.49 \mathrm{a}$ & $1.74 \pm 0.07 \mathrm{a}$ & $1.97 \pm 0.09 \mathrm{a}$ & $2.05 \pm 0.16 \mathrm{a}$ & $1.92 \pm 0.01 \mathrm{~b}$ \\
Longxiaodou 4 & $\mathrm{~T} 2$ & $1.95 \pm 0.23 \mathrm{a}$ & $1.88 \pm 0.04 \mathrm{a}$ & $1.95 \pm 0.05 \mathrm{a}$ & $2.14 \pm 0.11 \mathrm{a}$ & $2.43 \pm 0.07 \mathrm{a}$ \\
& $\mathrm{T} 3$ & $1.74 \pm 0.10 \mathrm{a}$ & $1.68 \pm 0.06 \mathrm{a}$ & $1.69 \pm 0.05 \mathrm{~b}$ & $1.33 \pm 0.03 \mathrm{~b}$ & $1.72 \pm 0.02 \mathrm{c}$ \\
天津红 & $\mathrm{T} 4$ & $1.59 \pm 0.06 \mathrm{a}$ & $1.61 \pm 0.09 \mathrm{a}$ & $1.49 \pm 0.08 \mathrm{a}$ & $1.57 \pm 0.05 \mathrm{a}$ & $1.49 \pm 0.11 \mathrm{a}$ \\
Tianjinhong & $\mathrm{T} 5$ & $1.64 \pm 0.07 \mathrm{a}$ & $1.58 \pm 0.05 \mathrm{a}$ & $1.37 \pm 0.04 \mathrm{a}$ & $1.51 \pm 0.08 \mathrm{a}$ & $1.75 \pm 0.11 \mathrm{a}$ \\
& $\mathrm{T} 6$ & $1.47 \pm 0.03 \mathrm{a}$ & $1.36 \pm 0.02 \mathrm{~b}$ & $1.40 \pm 0.03 \mathrm{a}$ & $1.22 \pm 0.03 \mathrm{~b}$ & $1.43 \pm 0.06 \mathrm{a}$ \\
\hline
\end{tabular}

处理同图 1。同天内标以不同字母的值在 $P=0.05$ 水平上差异显著。

Treatments are the same as those given in Fig. 1. Values of SOD/CAT within the same day with different letters are significantly different at the 0.05 probability level.

S3307 可降低 SOD/CAT, 龙小豆 4 号处理 3 5 d 时, $\mathrm{T} 3$ 较 T2 分别显著降低 $13.33 \% 、 37.85 \%$ 和 $29.22 \%$; 天津红处理 $2 \mathrm{~d}$ 和 $4 \mathrm{~d}$ 时, T6 较 $\mathrm{T} 5$ 分别显著降低 $13.92 \%$ 和 $19.21 \%$ 。

\section{3 淹水胁迫及喷施 S3307 对小互幼苗叶片渗透 调节物质含量的影响}

2.3.1 对叶片脯氨酸含量的影响 由图6可知,
幼苗期淹水及喷施S3307处理后, 小豆叶片脯氨酸 含量表现为先升后降的趋势, 龙小豆 4 号和天津红 均在处理第 4 天时达到峰值, 各处理时间内脯氨酸 含量均为喷施 $\mathrm{S} 3307>$ 淹水胁迫 $>\mathrm{CK}$ 。龙小豆 4 号处理 $1 \sim 5 \mathrm{~d}$ 时, T2均显著高于 $\mathrm{T} 1$, 处理 $1 \mathrm{~d} 、 3 \mathrm{~d}$ 和 $5 \mathrm{~d}$ 时, $\mathrm{T} 3$ 较T2显著高出 $14.05 \% 、 11.44 \%$ 和 $8.72 \%$ 。天津红处 理 $1 \sim 5 \mathrm{~d}$ 时, T5均显著高于 $\mathrm{T} 4$, 处理 2 4 $\mathrm{d}$ 时, T6较 $\mathrm{T} 5$ 
显著高出 $29.18 \%$ 、31.79\%和 $13.69 \%$ 。

2.3.2 对叶片可溶性糖含量的影响 由图 7 可知, 淹水处理及喷施 S3307 后, 小互叶片可溶性糖含 量升高, 以应激和缓解淹水伤害。龙小豆 4 号处理 $1 \sim 5 \mathrm{~d}$ 时, 均为 $\mathrm{T} 2>\mathrm{T} 1$, 处理 $2 \sim 5 \mathrm{~d}$ 时, $\mathrm{T} 2$ 较 $\mathrm{T} 1$ 显著 高出 $31.56 \% 、 55.59 \% 、 68.42 \%$ 和 $22.82 \%$, 各时期内 $\mathrm{T} 3$ 与 $\mathrm{T} 2$ 间均无显著差异。天津红处理 1 5 d 时, T5 均显著高于 $\mathrm{T} 4$, 处理 $2 \mathrm{~d}$ 和 $4 \mathrm{~d}$ 时, T6 较 T5 显著高 出 $17.46 \%$ 和 $17.76 \%$ 。

\subsection{3 对叶片可溶性蛋白含量的影响 由图 8 可} 知, 淹水处理及喷施 S3307 后, 小豆叶片可溶性蛋 白含量呈先升高后降低趋势。龙小亘 4 号处理 $2 \sim 5 \mathrm{~d}$ 时， T2 较 T1 显著高出 $24.18 \% 、 70.88 \% 、 20.84 \%$ 和 $7.06 \%$, 处理 3 5 d 时, T3 较 T2 显著高出 $20.59 \%$ 、 $9.21 \%$ 和 $7.13 \%$ 。天津红处理 1 4 d 时, T5 较 T4 显著 高出 $4.61 \% 、 15.96 \% 、 65.34 \%$ 和 $93.36 \%$, 处理 $1 \sim 5 \mathrm{~d}$
时，T6 较 T5 显著高出 $17.60 \% 、 17.00 \% 、 17.23 \%$ 、 $58.16 \%$ 和 $55.23 \%$ 。

2.4 淹水胁迫及喷施 $\mathbf{S 3 3 0 7}$ 对小亘幼苗叶片激素 水平的影响

2.4.1 对叶片脱落酸(ABA)的影响 由图 9 可知, 幼苗期淹水处理后, 小豆叶片内 $\mathrm{ABA}$ 含量呈递增变 化趋势, 喷施 S3307 可进一步促进 ABA 含量增加, 不同处理时间内 $\mathrm{ABA}$ 含量均为喷施 $\mathrm{S} 3307>$ 淹水胁迫 $>\mathrm{CK}$ 。龙小亚 4 号处理 1 5 d 时, T2 均显著高于 $\mathrm{T} 1, \mathrm{~T} 3$ 均显著高于 $\mathrm{T} 2$ 。天津红处理 1 5 d 时, $\mathrm{T} 5$ 均显著高于 $\mathrm{T} 4$, 处理 $1 \mathrm{~d}$ 和 $2 \mathrm{~d}$ 时, T6 较 T5 显著高出 $24.01 \%$ 和 $25.36 \%$, 处理 $4 \mathrm{~d}$ 时, T6 较 T5 显著提高 $7.34 \%$ 。

2.4 .2 对叶片生长素(IAA)的影响 由图 10 可知, 幼苗期淹水处理后, 小五叶片内 IAA 含量大致呈升 高趋势。龙小亘 4 号处理 $2 \mathrm{~d}$ 时, T2 较 $\mathrm{T} 1$ 显著降低 $20.13 \%$ 。处理 $3 \sim 5 \mathrm{~d}$ 时, $\mathrm{T} 2$ 较 $\mathrm{T} 1$ 分别显著高出

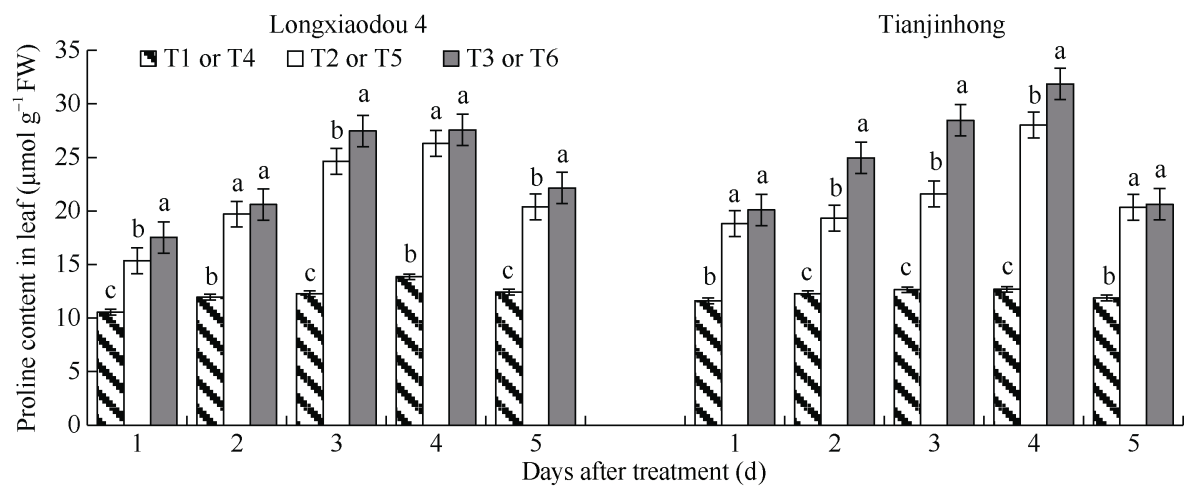

图 6 淹水胁迫及喷施 $\mathrm{S3307}$ 对小豆幼苗叶片脯氨酸含量的影响

Fig. 6 Effects of waterlogging stress and spraying $\mathbf{S 3 0 7}$ on proline content in leaf of seedlings of adzuki bean 处理同图 1。同天内标以不同字母的值在 $P=0.05$ 水平上差异显著。

Treatments are the same as those given in Fig. 1. Values of proline content within the same day with different letters are significantly different at the 0.05 probability level.

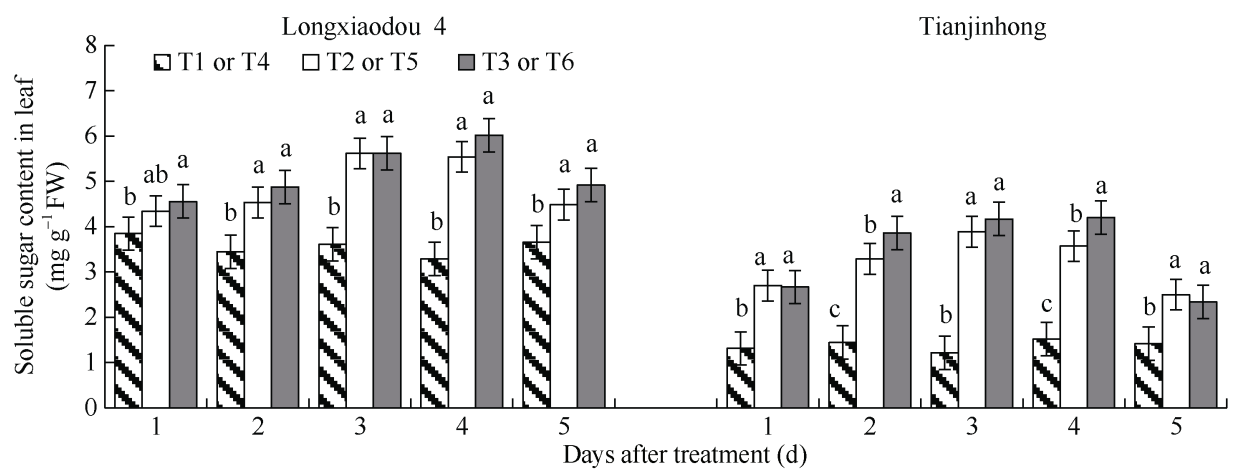

图 7 淹水胁迫及喷施 $\mathbf{S 3 3 0 7}$ 对小豆幼苗叶片可溶性糖含量的影响

Fig. 7 Effects of waterlogging stress and spraying S3307 on soluble sugar content in leaf of seedlings of adzuki bean 处理同图 1。同天内标以不同字母的值在 $P=0.05$ 水平上差异显著。

Treatments are the same as those given in Fig. 1. Values of proline content within the same day with different letters are significantly different at the 0.05 probability level. 
$28.00 \% 、 72.73 \%$ 和 $47.47 \%$; 而 $\mathrm{T} 3$ 均显著低于 $\mathrm{T} 2$, 降幅分别为 $23.56 \% 、 24.37 \%$ 和 $16.76 \%$ 。天津红处 理 $1 \mathrm{~d}$ 和 $2 \mathrm{~d}$ 时, T4、 $\mathrm{T} 5$ 和 $\mathrm{T} 6$ 之间差异不显著。处
理 3 5 d 时, T5 较 T4 显著高出 $102.35 \%$ 、56.04\%和 $58.77 \%$, T6 较 T5 显著下降 $33.92 \% 、 17.78 \%$ 和 $24.88 \%$ 。

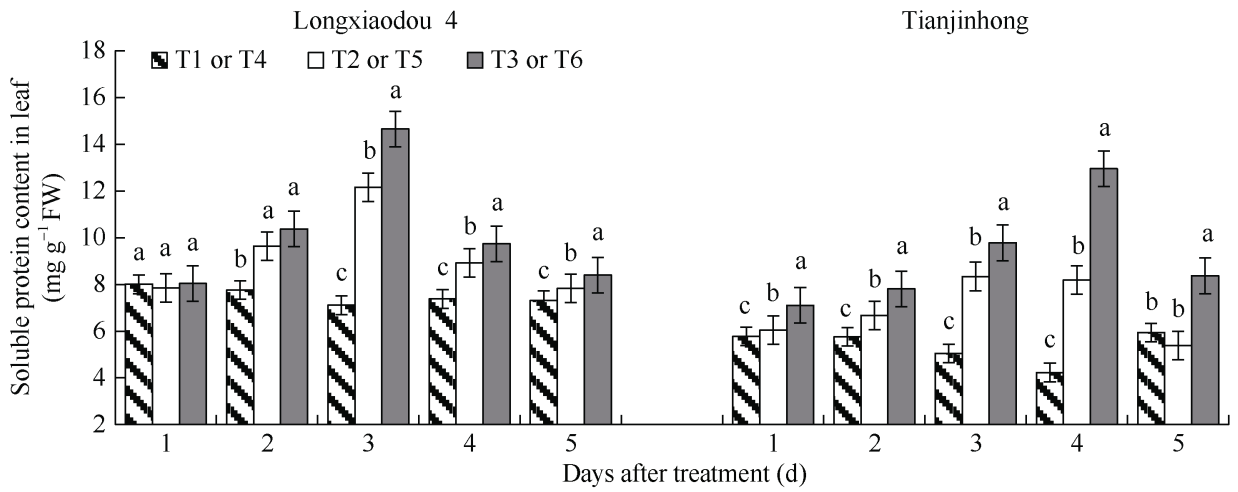

图 8 淹水胁迫及喷施 $\mathbf{S 3 3 0 7}$ 对小豆幼苗叶片可溶性蛋白含量的影响

Fig. 8 Effects of waterlogging stress and spraying S3307 on soluble protein content in leaf of seedlings of adzuki bean 处理同图 1。同天内标以不同字母的值在 $P=0.05$ 水平上差异显著。

Treatments are the same as those given in Fig. 1. Values of protein content within the same day with different letters are significantly different at the 0.05 probability level.

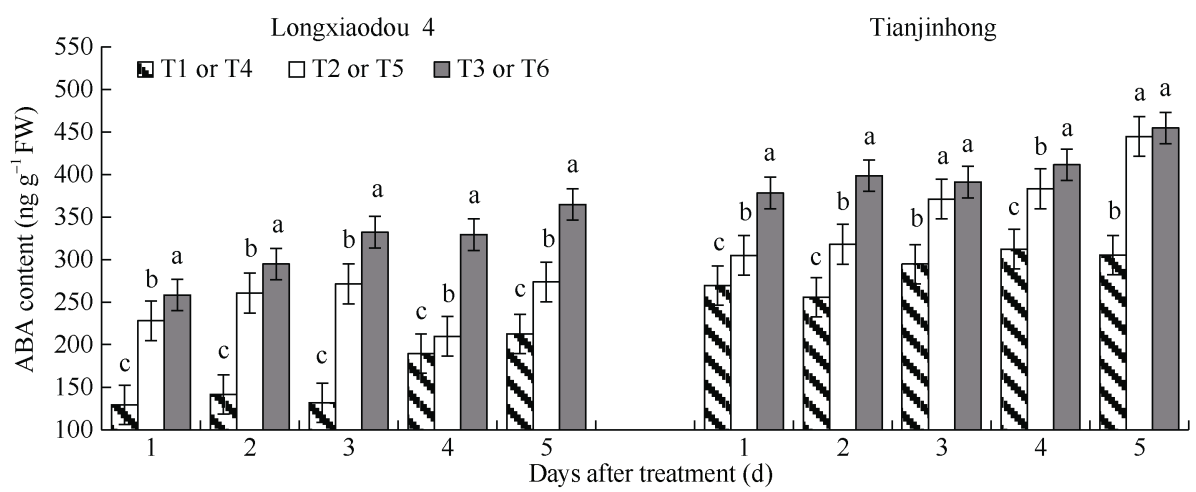

图 9 淹水胁迫及喷施 $\mathrm{S3307}$ 对小豆幼苗叶片 $\mathrm{ABA}$ 含量的影响

Fig. 9 Effects of waterlogging stress and spraying S3307 on ABA content in leaf of seedlings of adzuki bean 处理同图 1。同天内标以不同字母的值在 $P=0.05$ 水平上差异显著。

Treatments are the same as those given in Fig. 1. Values of ABA content within the same day with different letters are significantly different at the 0.05 probability level.

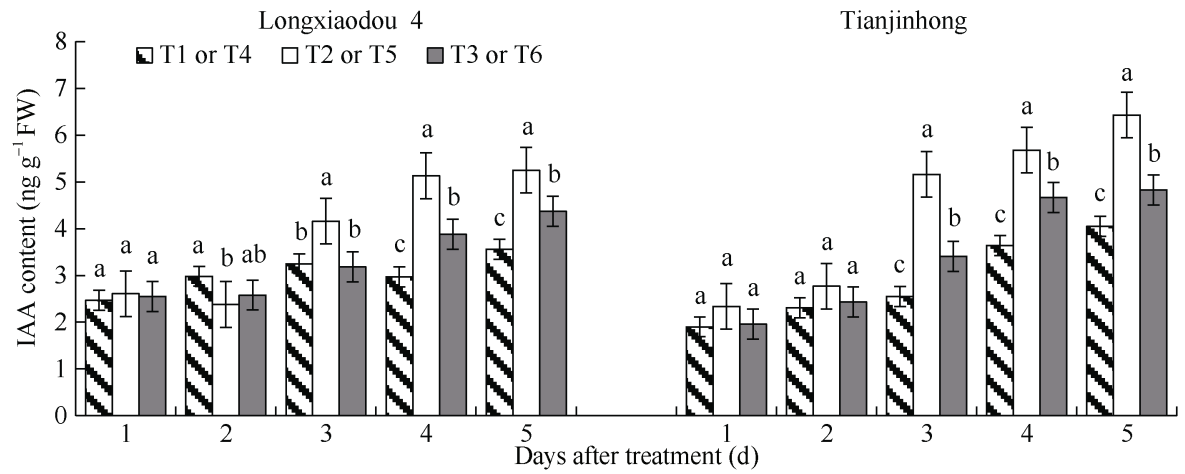

图 10 淹水胁迫及喷施 S3307 对小豆幼苗叶片 IAA 含量的影响

Fig. 10 Effects of waterlogging stress and spraying S3307 on IAA content in leaf of seedlings of adzuki bean 处理同图 1。同天内标以不同字母的值在 $P=0.05$ 水平上差异显著。

Treatments are the same as those given in Fig. 1. Values of IAA content within the same day with different letters are significantly different at the 0.05 probability level. 
2.4.3 对叶片水杨酸(SA)的影响 由图 11 可知, 幼苗期淹水处理引起小豆叶片内 SA 含量升高, 喷 施 S3307 有利于 SA 含量进一步提高。龙小亘 4 号 处理 2 $5 \mathrm{~d}$ 时, T2 较 T1 分别显著高 $27.01 \% 、 20.54 \%$ 、 $74.80 \%$ 和 $128.56 \%$; 处理 $3 \sim 5 \mathrm{~d}$ 时, T3 含量均高于
$\mathrm{T} 2$, 其中处理 $4 \mathrm{~d}$ 时 $\mathrm{T} 3$ 较 T2 显著高出 $16.12 \%$ 。天 津红处理 $2 \mathrm{~d} \sim 5 \mathrm{~d}$ 时, T5 较 T4 分别显著高 $19.22 \%$ 、 $54.06 \%$ 、93.11\%和 $116.39 \%$; 处理 3 5 d 时, T6 含量 均高于 $\mathrm{T} 5$, 其中处理 $4 \mathrm{~d}$ 时, T6 较 T5 显著高 $20.48 \%$ 。

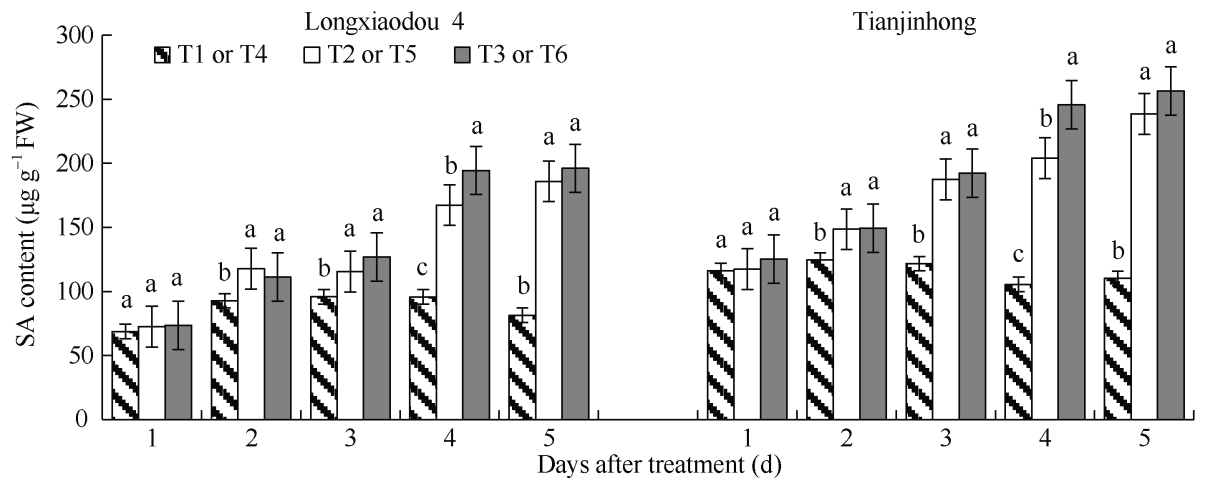

图 11 淹水胁迫及喷施 S3307 对小豆幼苗叶片 SA 含量的影响

Fig. 11 Effect of waterlogging stress and spraying S3307 on SA content in leaf of seedlings of adzuki bean 处理同图 1。同天内标以不同字母的值在 $P=0.05$ 水平上差异显著。

Treatments are the same as those given in Fig. 1. Values of SA content within the same day with different letters are significantly different at the 0.05 probability level.

\section{5 淹水胁迫及喷施 $\mathrm{S3307}$ 对小豆产量的影响} 由表 4 可知, 幼苗期淹水处理引起小亘产量下 降。方差分析结果表明, 2 年试验结果基本一致。龙 小亘 4 号处理 1 2 d 时, $\mathrm{T} 1$ 和 $\mathrm{T} 2$ 之间无显著差异; 处 理 3 5 d 时, $\mathrm{T} 2$ 均显著低于 $\mathrm{T} 1$, 单盆产量分别显著 降低 $4.54 \% \sim 8.34 \% 、 7.57 \% \sim 10.62 \%$ 和 $8.40 \%$ $12.61 \%$ 。天津红处理 1 2 d 时, T4 和 T5 之间无显著 差异; 处理 3 5 d 时, $\mathrm{T} 5$ 均显著低于 $\mathrm{T} 4$, 单盆产量分
别显著降低 $4.97 \%$ \% $59 \% 、 6.54 \%$ 8.00\%和 $10.01 \%$ $9.91 \%$ 。喷施 S3307 可一定程度缓解产量的降低, 龙 小豆 4 号处理 1 2 d 时, T3 和 $\mathrm{T} 2$ 之间无显著差异; 处 理 $4 \mathrm{~d}$ 时, $\mathrm{T} 3$ 均显著高于 $\mathrm{T} 2$, 单盆产量分别显著增 加 $2.85 \% \sim 6.18 \%$, 处理 $5 \mathrm{~d}$ 时, $\mathrm{T} 3$ 与 T2 之间无显著 差异。天津红处理 1 3 d 时, T6 和 T5 之间无显著差 异; 处理 4 5 d 时, T6 较 T5 显著提高 2.85\% 3.95\% 和 $1.80 \% \sim 3.66 \%$ 。

表 4 淹水胁迫及喷施 53307 对小豆单盆产量的影响

Table 4 Effects of waterlogging stress and spraying S3307 in seedling stage on yield per plot in adzuki bean (g)

\begin{tabular}{|c|c|c|c|c|c|c|c|}
\hline \multirow{2}{*}{$\begin{array}{l}\text { 年份 } \\
\text { Year }\end{array}$} & \multirow{2}{*}{$\begin{array}{c}\text { 品种 } \\
\text { Variety }\end{array}$} & \multirow{2}{*}{$\begin{array}{c}\text { 处理 } \\
\text { Treatment }\end{array}$} & \multicolumn{5}{|c|}{ 淹水天数 Waterlogging days } \\
\hline & & & $1 \mathrm{~d}$ & $2 \mathrm{~d}$ & $3 \mathrm{~d}$ & $4 \mathrm{~d}$ & $5 \mathrm{~d}$ \\
\hline \multirow[t]{6}{*}{2018} & 龙小豆 4 号 & $\mathrm{T} 1$ & $33.32 \pm 0.64 \mathrm{a}$ & $33.32 \pm 0.64 \mathrm{a}$ & $33.32 \pm 0.64 \mathrm{a}$ & $33.32 \pm 0.64 \mathrm{a}$ & $33.32 \pm 0.64 \mathrm{a}$ \\
\hline & Longxiaodou 4 & $\mathrm{~T} 2$ & $32.31 \pm 0.32 \mathrm{a}$ & $31.83 \pm 0.41 \mathrm{a}$ & $30.54 \pm 0.32 \mathrm{~b}$ & $29.78 \pm 0.29 \mathrm{~b}$ & $29.12 \pm 0.18 \mathrm{~b}$ \\
\hline & & $\mathrm{T} 3$ & $32.78 \pm 0.43 \mathrm{a}$ & $32.50 \pm 0.27 \mathrm{a}$ & $31.91 \pm 0.46 \mathrm{ab}$ & $31.62 \pm 0.48 \mathrm{a}$ & $30.56 \pm 0.35 b$ \\
\hline & 天津红 & $\mathrm{T} 4$ & $27.36 \pm 0.31 \mathrm{a}$ & $27.36 \pm 0.31 \mathrm{a}$ & $27.36 \pm 0.31 \mathrm{a}$ & $27.36 \pm 0.31 \mathrm{a}$ & $27.36 \pm 0.31 \mathrm{a}$ \\
\hline & Tianjinhong & T5 & $26.65 \pm 0.27 \mathrm{a}$ & $26.63 \pm 0.11 \mathrm{a}$ & $26.00 \pm 0.11 \mathrm{~b}$ & $25.57 \pm 0.18 \mathrm{~b}$ & $24.62 \pm 0.18 \mathrm{c}$ \\
\hline & & T6 & $27.20 \pm 0.16 \mathrm{a}$ & $27.24 \pm 0.28 \mathrm{a}$ & $26.55 \pm 0.24 \mathrm{ab}$ & $26.58 \pm 0.18 \mathrm{a}$ & $25.52 \pm 0.19 \mathrm{~b}$ \\
\hline \multirow[t]{6}{*}{2019} & 龙小豆 4 号 & $\mathrm{T} 1$ & $30.37 \pm 0.22 \mathrm{a}$ & $30.37 \pm 0.22 \mathrm{a}$ & $30.37 \pm 0.22 \mathrm{a}$ & $30.37 \pm 0.22 \mathrm{a}$ & $30.37 \pm 0.22 \mathrm{a}$ \\
\hline & Longxiaodou 4 & $\mathrm{~T} 2$ & $30.12 \pm 0.39 \mathrm{a}$ & $29.85 \pm 0.39 \mathrm{a}$ & $28.92 \pm 0.24 \mathrm{~b}$ & $28.07 \pm 0.25 \mathrm{~b}$ & $27.82 \pm 0.86 \mathrm{~b}$ \\
\hline & & $\mathrm{T} 3$ & $30.27 \pm 0.16 \mathrm{a}$ & $29.97 \pm 0.32 \mathrm{a}$ & $29.73 \pm 0.17 \mathrm{a}$ & $28.87 \pm 0.13 \mathrm{a}$ & $28.32 \pm 0.25 \mathrm{~b}$ \\
\hline & 天津红 & $\mathrm{T} 4$ & $23.62 \pm 0.39 \mathrm{a}$ & $23.62 \pm 0.39 \mathrm{a}$ & $23.62 \pm 0.39 \mathrm{a}$ & $23.62 \pm 0.39 \mathrm{a}$ & $23.62 \pm 0.39 \mathrm{a}$ \\
\hline & Tianjinhong & $\mathrm{T} 5$ & $22.57 \pm 1.07 \mathrm{a}$ & $22.70 \pm 0.50 \mathrm{a}$ & $22.30 \pm 0.20 \mathrm{~b}$ & $21.73 \pm 0.22 \mathrm{~b}$ & $21.28 \pm 0.15 \mathrm{c}$ \\
\hline & & $\mathrm{T} 6$ & $23.45 \pm 0.33 \mathrm{a}$ & $23.10 \pm 0.33 \mathrm{a}$ & $22.92 \pm 0.13 \mathrm{ab}$ & $22.88 \pm 0.12 \mathrm{a}$ & $22.40 \pm 0.16 \mathrm{~b}$ \\
\hline
\end{tabular}

处理同图 1。同天内标以不同字母的值在 $P=0.05$ 水平上差异显著。

Treatments are the same as those given in Fig. 1. Values of yield within the same day with different letters are significantly different at the 0.05 probability level. 


\section{3 讨论}

淹水会严重破坏植物体内水分平衡, 并且引起 土壤缺氧, 对植物的生理代谢造成严重影响, 其受 影响程度随淹水强度和持续时间加重。在淹水逆境 下, 植物的 $R O S$ 代谢失衡, 导致 $\mathrm{H}_{2} \mathrm{O}_{2}$ 等物质过度积 累。正常条件下, $\mathrm{H}_{2} \mathrm{O}_{2}$ 的产生和清除过程基本保持一 种精细的平衡状态，淹水胁迫一旦打破这种平衡, 就会出现 $\mathrm{H}_{2} \mathrm{O}_{2}$ 的积累, 由于它具有较高的氧化还原 活性, 所以能引起细胞内大分子氧化损伤, 最终抑 制植物体内多种生理生化反应, 影响植物体内的调 控和代谢 ${ }^{[18]}$ 。MDA是细胞膜过氧化的产物, 可与细 胞膜上的蛋白质、酶等结合, 使之失活, 破坏生物膜 结构和功能, 影响细胞的物质代谢。本试验结果表 明, 淹水引起小互体内 $\mathrm{H}_{2} \mathrm{O}_{2}$ 和MDA含量增加, 说明 淹水胁迫导致细胞膜受损, 影响细胞代谢功能, 这 与尤东玲等 ${ }^{[3]}$ 、齐玉军等 ${ }^{[19]}$ 在不同作物上的研究结 果相似。在逆境条件下应用S3307后, 会缓解胁迫对 植物造成的危害, 有研究指出 ${ }^{[8,11]}$, 淹水胁迫后叶片 喷施S3307能够有效降低受淹作物的 $\mathrm{H}_{2} \mathrm{O}_{2}$ 和MDA含 量, 保证作物在淹水逆境下的正常生理代谢和生化 进程, 本研究也表明, 喷施S3307能够显著抑制淹水 条件下小豆叶片 $\mathrm{H}_{2} \mathrm{O}_{2}$ 和MDA含量的增加, 减轻淹水 对细胞的过氧化作用, 维持细胞膜的流动性和稳定 性, 这是S3307增强小互抗逆性的生理原因之一。

为了抵御淹水胁迫下 $R O S$ 的毒害作用, 植物体 内的抗氧化酶类能清除自由基, 缓解淹水胁迫对植 物造成的伤害 ${ }^{[20]}$ 。抗氧化酶是指植物体内存在的一 系列可以防止自由基对植物造成毒害的具有清除活 性氧自由基功能的酶, 如保护酶系统主要包括 SOD、POD和CAT等。植物通过SOD、POD和CAT 三者协同作用，使体内的氧自由基维持在较低水平， 可以在一定程度上减缓或防御逆境胁迫 ${ }^{[21]}$ 。SOD的 主要作用是清除超氧根阴离子 $\left(\mathrm{O}_{2}{ }^{-}\right)$, 但同时产生 $\mathrm{H}_{2} \mathrm{O}_{2}$, 而POD和CAT通过酶促作用降解多余的 $\mathrm{H}_{2} \mathrm{O}_{2}$ 等ROS, 避免植物遭受因胁迫引起的过氧化伤害。有 研究指出, SOD/POD、SOD/CAT比值的提高会进一 步增加植物体氧化胁迫 ${ }^{[22]}$ 。相关研究指出淹水条件 下喷施S3307能显著提高大豆体内SOD、POD活性 ${ }^{[1]}$, 杨文钰等 ${ }^{[23]}$ 指出, S3307能减少MDA含量, 提高 SOD、POD和CAT活性, 说明S3307具有在逆境条件 下提高作物抗氧化酶活性的功能, 增强作物的抗逆 能力。本研究发现, 淹水胁迫诱导小豆体内保护酶
活性不同程度提高, 这是作物开启了抵御逆境胁迫 的自身保护机制，但这种机制只能持续短暂时间， 随着胁迫时间延长, 保护酶活性即开始下降, 这可 能是其保护机制的临界阈值。喷施 S3307能进一步显 著提高保护酶活性，尤其对CAT活性更为明显，同 时可有效降低SOD/POD、SOD/CAT比值, 说明S3307 可系统地协调保护酶体系运行, 全面提高细胞抗氧 化能力, 缓解或消除ROS的过氧化反应。

渗透调节是植物通过调节相应的代谢机制而维 持正常生命活动的重要调节机制之一。逆境条件下 细胞能主动积累可溶性糖、可溶性蛋白和脯氨酸等 有机渗透调节物质, 来调节细胞的渗透势, 保护植 物组织内各种酶类和细胞膜结构的正常功能 ${ }^{[3]}$ 。这

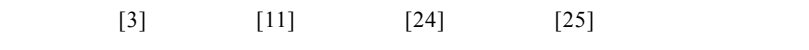
得到广泛验证。本研究结果表明, 淹水胁迫导致小 豆叶片的脯氨酸、可溶性糖和可溶性蛋白含量提高, 尤其是脯氨酸含量得到显著提高, 可有效缓解淹水 带来的伤害。因为脯氨酸可以通过维持细胞膨胀或 渗透平衡来赋予植物胁迫耐受性, 从而稳定膜结构, 防止电解质泄漏。喷施S3307能进一步提高渗透调节 物质含量, 尤其显著提高了可溶性蛋白的含量, 能 够促进细胞液浓度提高, 增加细胞持水组织中的非 结冰水, 有利于提高植物的抗逆性, 这也是 $\mathrm{S} 3307$ 提 高植物抗逆性的生理原因之一。

内源激素在植物生长发育中发挥重要作用, 不 同激素之间存在相互促进和相互拮抗的生理效应, 激素间的动态平衡对植物生长发育的调节作用更为 重要, 激素含量变化在响应非生物胁迫中扮演关键 角色 ${ }^{[26]}$ 。研究表明, 淹水胁迫抑制 IAA、赤霉素 $(\mathrm{GA})$ 和细胞分裂素(CTK)合成, 同时增加 $\mathrm{ABA}$ 和乙烯合 成 ${ }^{[27]}$ 。本研究表明, 淹水胁迫引起小豆叶片内 $\mathrm{ABA}$ 、 IAA 和 SA 含量增加, 并随胁迫时间延长呈显著升高 趋势, 这与陈博雯等 ${ }^{[28]}$ 的研究结果相似。但与潘向 艳等 ${ }^{[29]}$ 的研究结果有所不同, 其研究表明, 淹水 $4 \mathrm{~d}$ 内, 叶片体内 $\mathrm{ABA}$ 含量先升后降、IAA 含量先降后 升。这表明不同植物对淹水胁迫的响应存在差别, 尤其在激素水平动态平衡层面, 其抵御胁迫的内在 机制尚需进一步研究。S3307 对作物生长发育有多 种调控效应，包括调控内源激素、增强抗性等 ${ }^{[11]}$ 。 本研究结果表明, 喷施 S3307 能够促进 ABA 和 SA 进一步提高, 同时有效调控 IAA 含量增加速率, 进 而提高小豆的抗性。分析其原因可能是由于 $\mathrm{ABA}$ 含 量的提高, 以及 IAA 含量的相对降低, 共同调节和 
启动植物自身保护系统，短时抑制作物生长发育、 降低损耗, 维持正常的生理活动, 抵御胁迫伤害, 安全度过胁迫时期。

淹水胁迫导致作物产量下降，不同时期的影响 存在差异。于奇等 ${ }^{[8]}$ 研究表明, 开花期和结荚期淹水 均可降低绿豆产量, 其中开花期淹水胁迫减产更严 重, 尤东玲等 ${ }^{[3]}$ 指出, 不同时期淹水对玉米减产影 响不同, 其中以苗期对涝渍最为敏感。本研究结果 表明, 小亘幼苗淹水胁迫 $3 \mathrm{~d}$ 就可引起产量显著降 低。喷施 S3307 能缓解淹水胁迫引起的产量损失, 在 同为互科作物的大豆 ${ }^{[9]}$ 、绿豆 ${ }^{[8]}$ 等均有验证, 本研究 也得到相同结果，喷施 S3307 能有效缓解淹水对小 豆产量的影响, 对龙小豆 4 号品种更为明显。

本研究结果表明，喷施 S3307 能有效提高小亘 抗性, 缓解淹水胁迫。我们认为主要是 S3307 引起 ABA 含量增加, IAA 含量降低, 调节了内源激素的 动态平衡的结果。该调节通过以下 2 个途径进行: 一 是通过提高脯氨酸和可溶性糖等渗透调节物质来维 持细胞膜的正常生理功能，抵御胁迫伤害，其中脯 氨酸含量的提高可能是 S3307 促进了谷氨酸向脯氨 酸的转化, 因为逆境条件下脯氨酸的主要来源就是 谷氨酸合成途径，但需进一步验证；可溶性糖含量 提高的原因可能是因为 S3307 具有提高光合作用和 内源 $\mathrm{ABA}$ 的生理功能，一方面因光合作用增强进而 提高了光合产物(单糖)含量, 另一方面因内源 $\mathrm{ABA}$ 与蔗糖的合成呈正相关的关系, ABA 含量的提高促 进了某些不可溶碳水化合物向可溶的蔗糖进行转化, 通过上述两方面提高了小互的可溶性糖含量进而提 高抗性。二是 S3307 通过提高保护酶活性进而清除 ROS 的过氧化反应, 其主要原因可能是淹水条件下, 内源激素含量的变化促进了小豆体内蛋白合成的生 化反应，进而提高某些酶蛋白含量，这其中就包括 了 SOD 酶蛋白、POD 酶蛋白和 CAT 酶蛋白等, 这 些保护酶含量的增加以及活性的提高, 增强了小亘 对 ROS 物质和 MDA 的清除, 进一步提高小互在淹 水胁迫下的抗性。

有关喷施 S3307 缓解淹水胁迫的细胞结构、细 胞膜脂肪酸组分和膜脂稳定性、非酶抗氧化剂含量、 以及相关耐淹基因启动和表达调控等生理和分子机 制还需进一步挖掘。

\section{4 结论}

幼苗期淹水胁迫引起小豆叶片内 $\mathrm{H}_{2} \mathrm{O}_{2}$ 和 MDA
含量显著增加，同时诱导增强 SOD 和 POD 活性，脯 氨酸、可溶性蛋白和可溶性糖均有所提高, 引起 ABA、IAA 和 SA 含量增加, 并最终导致产量下降。 喷施 S3307 处理减缓小亘的胁迫损伤, 其相对降低 了小豆叶片内 $\mathrm{H}_{2} \mathrm{O}_{2}$ 和 MDA 含量; 增强小豆叶片 SOD 和 POD 的活性; 进一步增加脯氨酸和可溶性蛋 白含量，显著减轻细胞膜质过氧化作用，同时提高 $\mathrm{ABA}$ 和 SA 含量、有效抑制 IAA 含量上升幅度, 整 体提高小豆对淹水胁迫的抗性，进而减缓了小豆因 水分胁迫造成的产量降低。S3307 处理对不同品种 小亘的调控效应有所不同，但可用于小豆抗涝生产, 缓解淹水危害。

\section{References}

[1] 赵东晓, 董亚茹, 孙景诗, 杜建勋, 陈传杰, 娄齐年, 梁明芝, 王照红. 淹水胁迫对桑树幼苗生长和生理特性的影响. 山东 农业科学, 2018, 50(11): 55-57.

Zhao D X, Dong Y R, Sun J S, Du J X, Chen C J, Lou Q N, Liang M Z, Wang Z H. Effects of waterlogging stress on seedling growth and physiological characteristics of mulberry. Shandong Agric Sci, 2018, 50(11): 55-57 (in Chinese with English abstract).

[2] Shabala S. Physiological and cellular aspects of phytotoxicity tolerance in plants: the role of membrane transporters and implications for crop breeding for waterlogging tolerance. New Phytol, 2011, 190: 289-298.

[3] 尤东玲, 张星, 于康珂, 李潮海, 王群. 亚精胺酸对淹水胁迫 下玉米幼苗生长和生理特性的影响. 玉米科学, 2016, 24(1): $74-80$.

You D L, Zhang X, Yu K K, Li C H, Wang Q. Effect of exogenous spermidine on growth and physiological properties of maize seedling under waterlogging stress. J Maize Sci, 2016, 24(1): 74-80 (in Chinese with English abstract).

[4] Normile D. Reinventing rice to feed the world. Science, 2008, 321: 330-333.

[5] 陈鹭真, 林鹏, 王文卿. 红树植物淹水胁迫响应研究进展. 生 态学报, 2006, 26: 586-593.

Chen L Z, Lin P, Wang W Q. Mechanisms of mangroves waterlogging resistance. Acta Ecol Sin, 2006, 26: 586-593 (in Chinese with English abstract).

[6] 吴麟, 张伟伟, 葛晓敏, 唐罗忠. 植物对淹水胁迫的响应机制 研究进展. 世界林业研究, 2012, 25(6): 27-33.

Wu L, Zhang W W, Ge X M, Tang L Z. A review of the response mechanisms of plants to waterlogging stress. World For Res, 2012, 25(6): 27-33 (in Chinese with English abstract).

[7] 余卫东, 冯利平, 胡程达, 彭记永. 苗期涝渍对黄淮地区夏玉 米生长和产量的影响. 生态学杂志, 2015, 34: 2161-2166.

Yu W D, Feng L P, Hu C D, Peng J Y. Effects of waterlogging during seedling stage on the growth and yield of summer maize in Huang-Huai region. Chin J Ecol, 2015, 34: 2161-2166 (in Chinese with English abstract).

[8] 于奇, 冯乃杰, 王诗雅, 左官强, 郑殿峰. S3307 对始花期和始 
粒期淹水绿豆光合作用及产量的影响. 作物学报, 2019, 45: 1080-1089.

Yu Q, Feng N J, Wang S Y, Zuo G Q, Zheng D F. Effects of S3307 on the photosynthesis and yield of mung bean at R1 and R5 stages under waterlogging stress. Acta Agron Sin, 2019, 45: 1080-1089 (in Chinese with English abstract).

[9] 张洪鹏, 张盼盼, 李冰, 李东, 刘文彬, 冯乃杰, 郑殿峰. 烯效 唑对淹水胁迫下大豆叶片光合特性及产量的影响. 中国油料 作物学报, 2016, 38: 611-618.

Zhang H P, Zhang P P, Li B, Li D, Liu W B, Feng N J, Zheng D F. Effects of uniconazole on leaf photosynthetic characteristics and yield of soybean under waterlogging stress. Chin J Oil Crop Sci, 2016, 38: 611-618 (in Chinese with English abstract).

[10] 项洪涛, 李琬, 何宁, 王雪扬, 郑殿峰, 王胓删, 粱晓艳, 唐晓 东, 李一丹. 苗期胁迫下烯效唑对红小豆根系抗寒生理及产 量的影响. 草业学报, 2019, 28(7): 92-102.

Xiang H T, Li W, He N, Wang X Y, Zheng D F, Wang T T, Liang X Y, Tang X D, Li Y D. Effects of S3307 on physiology of chilling resistance in root and yield of adzuki bean under low temperature stress during seeding stage. Acta Pratac Sin, 2019, 28(7): 92-102 (in Chinese with English abstract).

[11] 张洪鹏, 张盼盼, 李冰, 李东, 刘文彬, 冯乃杰, 郑殿峰. 烯效 唑对淹水胁迫下大豆农艺形状及生理生化指标的影响. 中国 油料作物学报, 2017, 39(5): 655-663.

Zhang H P, Zhang P P, Li B, Li D, Liu W B, Feng N J, Zheng D F. Effects of uniconazole on alleviation of waterlogging stress in soybean. Chin J Oil Crop Sci, 2017, 39(5): 655-663 (in Chinese with English abstract).

[12] 赵宏伟, 王喆, 雎炤珺, 李晓, 张妍, 张盛楠. 分藍期冷水胁 迫对寒地粳稻根系生理特性及产量的影响. 东北农业大学学 报, 2019, 50(12): 10-20.

Zhao H W, Wang Z, Qu Z J, Li X, Zhang Y, Zhang S N. Effect of cold water stress at tillering stage on physiological characteristics and yield of japonica rice roots in cold region. J Northeast Agric Univ, 2019, 50(12): 10-20 (in Chinese with English abstract).

[13] 梁晓艳, 刘春娟, 冯乃杰, 郑殿峰, 卢洁春, 项洪涛. 两种生 长调节剂对大豆叶片昼夜同化物生理代谢及产量的影响. 大 豆科学, 2019, 38: 244-250.

Liang X Y, Liu C J, Feng N J, Zheng D F, Lu J C, Xiang H T. The Effects of two growth regulators on diurnal assimilate physiological metabolism variation of soybean leaves and yield. Soybean Sci, 2019, 38: 244-250 (in Chinese with English abstract).

[14] 刘洋, 郑殿峰, 冯乃杰, 张红梅, 张盼盼, 陈文浩, 刘涛, 龚屾. 鼓粒期叶施烯效唑和激动素对绿豆叶片碳代谢及籽粒产量的 影响. 西南农业学报, 2016, 29: 1584-1589.

Liu Y, Zheng D F, Feng N J, Zhang H M, Zhang P P, Chen W H, Liu T, Gong S. Effects of spraying uniconazole and kinetin in leaves of carbon metabolism and grain yield on mung bean in R6. Southwest China J Agric Sci, 2016, 29: 1584-1589 (in Chinese with English abstract)

[15] 李合生, 孙群, 赵世杰. 植物生理生化试验原理和技术. 北京: 高等教育出版社, 2000. pp 167-169, 184-185.

Li H S, Sun Q, Zhao S J. Principles and Techniques of Plant Physiological Biochemical Experimental. Beijing: Higher Education Press, 2000. pp 167-169, 184-185 (in Chinese).

[16] 张宪政. 作物生理研究法. 北京: 农业出版社, 1992. pp
201-202.

Zhang X Z. Crop Physiology Research Method. Beijing: Chinese Agriculture Press, 1992. pp 201-202 (in Chinese).

[17] 范建新, 邓仁菊, 王永清, 罗丽娜, 韩树全, 刘荣. 火龙果茎 段及花药愈伤组织内源激素含量的测定. 分子植物育种, 2017 , 15: 5093-5102.

Fan J X, Deng R J, Wang Y Q, Luo L N, Han S Q, Liu R. Determination of endogenous hormones in callus originated from stem and anther culture of pitaya. Mol Plant Breed, 2017, 15: 5093-5102 (in Chinese with English abstract).

[18] 宋喜贵, 余小平. 植物体内过氧化氢的产生及其生理作用. 连 云港示范高等专科学校学报, 2010, (4): 99-103.

Song X G, She X P. The generation and the role of hydrogen peroxide in plant. J Lianyungang Teach Coll, 2010, (4): 99-103 (in Chinese with English abstract).

[19] 齐玉军, 方传文, 徐泽俊, 王晓军, 孙东雷, 市能飞, 王幸. 外 源二乙基二硫代氨基甲酸钠对花期淹水大豆根系抗氧化系统 的影响. 中国油料作物学报, 2019, 41: 577-587.

Qi Y J, Fang C W, Xu Z J, Wang X J, Sun D L, Bian N F, Wang X. Effect of exogenous sodium diethyldithiocarbamate on antioxidation system in soybean root on waterlogging at flowering stage. Chin J Oil Crop Sci, 2019, 41: 577-587 (in Chinese with English abstract).

[20] 孙小艳, 陈铭, 李彦强, 吴照祥, 钟永达, 余发新. 淹水胁迫 下北美鹅掌楸无性系生理生化响应差异. 植物生理学报, 2018, 54: 473-482.

Sun X Y, Chen M, Li Y Q, Wu Z D, Zhong Y D, Yu F X. Variations in physiological and biochemical responses in clones of Liriodendron tulipifera under flooding stress. Plant Physiol J, 2018, 54: 473-482 (in Chinese with English abstract).

[21] 李春燕, 徐雯, 刘立伟, 杨景, 朱新开, 郭文善. 条件下拔节 期小麦叶片内源激素含量和抗氧化酶活性的变化. 应用生态 学报, 2015, 26: 2015-2022.

Li C Y, Xu W, Liu L W, Yang J, Zhu X K, Guo W S. Changes of endogenous hormone contents and antioxidative enzyme activities in wheat leaves under low temperature stress at jointing stage. Chin J Appl Ecol, 2015, 26: 2015-2022 (in Chinese with English abstract).

[22] Kanazawa S, Sano S, Koshiba T, Ushimaru T. Changes in antioxidative enzymes in cucumber cotyledons during natural senescence: comparison with those during dark-induced senescence. Physiol Plant, 2010, 109: 211-216.

[23] 杨文钰, 徐精文, 张鸿. 烯效唑对秧苗抗寒性的影响及其作用 机理研究. 杂交水稻, 2003, 18(2): 53-57.

Yang W Y, Xu J W, Zhang H. Studies on action mechanism and effect of uniconzole (S-3307) on cold resistance of rice seedlings. Hybrid Rice, 2003, 18(2): 53-57 (in Chinese with English abstract).

[24] 张永平, 入倩楠, 张文献, 田守波, 许爽, 范红伟. 淹水胁迫 及胁迫解除对甜瓜幼苗呼吸等生理代谢的影响. 中国蔬菜, 2019, (11): 41-48.

Zhang Y P, Diao Q N, Zhang W X, Tian S B, Xu S, Fan H W. Effects of waterlogging stress and stress relieve on respiration and other physiological metabolisms of melon seedlings. China Veget, 2019, (11): 41-48 (in Chinese with English abstract).

[25] 王华, 侯瑞贤, 李晓峰, 朱红芳, 朱玉英, 侯喜林. 淹水胁迫 对不结球白菜渗透调节物质含量的影响. 植物生理学报, 2013, 
49: 29-33.

Wang H, Hou R X, Li X F, Zhu H F, Zhu R Y, Hou X L. Effects of waterlogging stress on contents of osmotic adjustment substances in pak-choi (Brassica campestris L. ssp. chinensis Makino). Plant Physiol J, 2013, 49: 29-33 (in Chinese with English abstract).

[26] 段娜, 贾玉奎, 徐军, 陈海玲, 孙鹏. 植物内源激素研究进展. 中国农学通报, 2015, 31(2): 159-165.

Duan N, Jia Y K, Xu J, Chen H L, Sun P. Research progress on plant endogenous hormones. Chin Agric Sci Bull, 2015, 31(2): 159-165 (in Chinese with English abstract).

[27] 严雯奕, 叶胜海, 董彦君, 金庆生, 张小明. 植物叶片衰老相 关研究进展. 作物杂志, 2010, (4): 4-9.

Yan W Y, Ye S H, Dong Y J, Jin Q S, Zhang X M. Research progress related to plant leaf senescence. Crops, 2010, (4): 4-9 (in
Chinese with English abstract).

[28] 陈博雯, 袁剑英, 覃子海, 张烨, 肖玉菲, 张晓宁, 刘海龙. 淹 水胁迫中澳洲茶树内源激素动态变化. 山西农业科学, 2019, 47: 573-576.

Chen B W, Yuan J Y, Qin Z H, Zhang Y, Xiao Y F, Zhang X N, Liu H L. Dynamic changes of endogenous hormones in $\mathrm{Me}$ laleuca alternifolia under flooding stress. J Shanxi Agric Sci, 2019, 47: 573-576 (in Chinese with English abstract).

[29] 潘向艳, 季孔庶, 方彦. 淹水胁迫下杂交鹅掌楸无性系叶片内 源激素含量的变化. 南京林业大学学报(自然科学报), 2008, 32(1): 29-32.

Pan X Y, Ji K S, Fang Y. Changes in contents of endogenous hormones in different clones of Liriodendron chinense $\times L$. tulipifera under flooding stress. J Nanjing For Univ (Nat Sci Edn), 2008, 32(1): 29-32 (in Chinese with English abstract). 